\title{
SSynthesis
}

International Scientific Conference of IT and Business-Related Research

\section{UNAPREĐENJE TEKSTILNE INDUSTRIJE SRBIJE KROZ EDUKACIJU ZAPOSLENIH}

\author{
IMPROVING THE TEXTILE INDUSTRY IN SERBIA \\ THROUGH EMPLOYEE EDUCATION
}

\author{
Snežana Poznanović, Branislava Lazić \\ Visoka tekstilna strukovna škola za dizajn, tehnologiju i menadžment, Beograd, Srbija
}

\begin{abstract}
Apstrakt:
Cilj rada je utvrđivanje stanja tekstilne industrije Srbije u pogledu kompetentnosti kadrova i proširivanje veza visokih tekstilnih strukovnih škola koje školuju kadrove za tekstilnu industriju sa preduzećima tekstilne industrije u cilju usaglašavanja sadržaja studijskih programa i načina realizacije nastave sa potrebama tekstilne industrije. Nemački model dualnog sistema strukovnog obrazovanja predložen je kao najuspešniji za stvaranje kadrova sa znanjima, kompetencijama i veštinama neophodnim za uspešan rad, a time i povećanje konkurentnosti preduzeća tekstilne industrije na domaćem i stranom tržištu. Posebno se ističu mesto i uloga menadžmenta preduzeća u stvaranju uslova za produkovanje kompetentnog kadra za potrebe tekstilne industrije.
\end{abstract}

\section{Ključne reči:}

tekstilna industrija, upravljanje ljudskim resursima, uloga menadžmenta, edukacija zaposlenih, strukovno obrazovanje.

\section{UVOD}

Tekstilna industrija je veoma značajna industrijska oblast jer proizvodi odeću za sedam milijardi ljudi i tekstilne materijale za tehničke namene. Ona je internacionalno povezana, pripada tradicionalnim granama prerađivačke industrije i zapošljava veliki broj jeftine i kvalifikovane, uglavnom ženske, radne snage. Tehnički i tehnološki je vrlo zahtevna. Da bi se odgovorilo tim zahtevima, neophodno je zapošljavati kvalifikovanu, stručnu radnu snagu, koja poseduje neophodne kompetencije, znanja i veštine i koja je spremna da odgovori svim izazovima koji se pred nju postavljaju u uslovima velikih fluktuacija i brzih promena na tržištu (UNEP, 1994; Jovanović, 2005).

Velika odgovornost je na menadžmentu preduzeća da napravi selekciju i izbor pravih kadrova. Posebno je značajna uloga menadžmenta preduzeća u stvaranju uslova za produkovanje kadrova po meri tekstilne industrije (Poznanović \& Muratović, 2014). To podrazumeva aktivno učešće menadžmenta preduzeća u oblikovanju nastavnog plana i programa visokoškolskih ustanova, uključujući i visoke tekstilne škole strukovnih studija, osmišljavanju programa stručne prakse studenata visokih škola u okviru preduzeća i pružanju pomoći u odvijanju stručne prakse potencijalnih budućih kadrova tekstilne industrije.

Visoke tekstilne strukovne škole, kao učesnik u društveno odgovornom partnerstu, imaju odgovornost prihvatanja partnerstva na način koji će doneti obostrane koristi i opravdati

\section{Abstract:}

The purpose of this paper is to deterrmine the current situation in the textile industry in Serbia in terms of employee competencies and expanding connections with high textile vocational schools that train young people to work in the domain of textile industry with the aim to harmonize the content the study programmes and teaching methods with the needs of textile industry. The German dual system of vocational education is considered to be the most successful for generating expert personnel with knowledge, competencies and skills necessary for successful business, and thus enhancing competitiveness of textile industry enterprises in the domestic and international markets. Special emphasis is placed on the position and role of enterprises management in ensuring necessary conditions for creating competent personnel that could respond properly to the needs of the textile industry.

\section{Key words:}

textile industry, human resource management, the role of management, employee education, vocational education.

postojanje ovih škola po sadržaju, obimu i načinu realizacije obrazovnog procesa po meri tekstilne industrije. Takođe, imaju odgovornost prema svojim studentima da im pruže sigurnost u sticanju znanja i veština koji su realno upotrebljivi, primenljivi i dobra osnova za dalje usavršavanje, sigurnost u većoj prolaznosti i bržem i lakšem nalaženju zaposlenja, kao i mogućnost boljeg snalaženja u okruženju koje je prepoznatljivo. To podrazumeva i saradnju sa međunarodnim organizacijama i institucijama, koje razvijaju programe i obezbeđuju sredstva za edukaciju zaposlenih u tekstilnoj industriji (Sl. glasnik RS, 1/2007). Kako bi došle do pravog rešenja, visoke tekstilne škole u Srbiji moraju sagledavati prednosti i nedostatke primera iz okruženja i oslanjati se na pozitivna iskustva, pre svega, evropskog prostora visokog strukovnog obrazovanja.

U ovom radu ispituje se mesto i uloga menadžmenta preduzeća tekstilne industrije u nalaženju pravog rešenja za probleme tekstilne industrije Srbije vezane za kompetencije budućih i aktuelnih zaposlenih i njihovo kontinuirano napredovanje.

\section{KRETANJA U TEKSTILNOJ INDUSTRIJI U SVETU I STANJE TEKSTILNE INDUSTRIJE SRBIJE}

Globalno, tekstilna industrija je od 1970. godine do danas pretrpela velike promene, koje se poklapaju sa strukturnim krizama u razvijenim zemljama sveta, procesom globalizacije 
i ubrzane liberalizacije svetske trgovine. Razvijene zemlje su nastojale da, uz restrukturiraje ka modnim industrijama, deo svoje tradicionalne proizvodnje premeste u zemlje sa jeftinijim troškovima proizvodnje (lohn poslovi, outward processing, cut \& make poslovi). Trgovina tekstilnim proizvodima se odvijala van GATT-a (General Agreement on Tariffs and Trade - Opšti sporazum o carinama i trgovini), tako da je bila ugrožena raznim protekcionističkim merama razvijenih zemalja.

Doradni poslovi bili su predmet saradnje nerazvijenih i razvijenih zemalja i oni su doneli obostrane koristi. Za nerazvijene zemlje značili su upoznavanje sa tržišnim načinom poslovanja, sigurnost plasmana i uposlenost kapaciteta, orijentisanog na izvoz. Za razvijene zemlje najveća korist bila je visoka zarada i profit, bez potrebe za preteranim strukturnim promenama $u$ sopstvenim tekstilnim industrijama i bez narušavanja sopstvenog socijalnog mira.

Početak 2005. godine predstavljao je prekretnicu, jer je prestao da važi Sporazum o tekstilu između zemalja članica Svetske trgovinske organizacije (WTO - World Trade Organization), čime je trgovina tekstilnim proizvodima između članica WTO potpuno liberalizovana, a konkurencija u svetskim okvirima postala mnogo oštrija. Ostvarila su se očekivanja da će iz ovakvih odnosa profitirati zemlje jugoistočne Azije, koje karakterišu niski troškovi radne snage i masovna proizvodnja. Tekstilna industrija zemalja centralne i istočne Evrope bila je najviše pogođena gubitkom tržišta Istočnog bloka, padom kupovne moći stanovništva i liberalizacijom trgovine, koja je rezultirala uvozom jeftinih proizvoda iz Azije. Industrija prediva i tkanina bila je mnogo više pogođena i oporavljala se mnogo sporije od odevne industrije (Keane \& te Velde, 2008; Stamenković et al., 2010).

Kratkoročne mere, neophodne za revitalizaciju tekstilne industrije Srbije obuhvataju i edukaciju radne snage. Svoju saradnju sa visokoškolskim ustanovama preduzeća tekstilne industrije sprovode i preko klastera koji u tekstilnoj/odevnoj grani čine proizvođači sirovina i gotovih odevnih predmeta, naučne i obrazovne institucije i vladine i nevladine organizacije. Dugoročne ili strateške mere obuhvataju i mere i aktivnosti za jačanje konkurentnosti i produktivnosti koje podstiču razvoj društva zasnovan na znanju i učenju tokom čitavog života, primenu inovacija, istraživanje i razvoj, razvoj i upotrebu informaciono-komunikacionih tehnologija, koje podižu konkurentnost i obezbeđuju bolje funkcionisanje tržišta i reformu obrazovnog sistema (Ministarstvo ekonomije i regionalnog razvoja RS, 2011; Ministarstvo za nauku i tehnologiju RS, 2010). U izvesnoj meri razvoj tekstilne industrije u Srbiji zavisi od programa međunarodnih finansijskih organizacija i donacija stranih vlada.

Najveće zamerke inostranih stručnjaka odnose se, pored nedostatka i zastarelosti opreme, na lošu organizaciju same proizvodnje i nedostatak stručnih timova i iskustva i stručnosti radne snage. Zamerke su i na sporo reagovanje na zahteve kupaca i nedostatak definisanog tržišta (proizvodnja za tačno određene kupce). Nasuprot tome, ističe se fleksibilnost radne snage, spremnost na učenje i usavršavanje i sposobnost za brzo ovladavanje novim sistemima.

U tekstilnoj industriji Srbije često se sreće problem nekompetentnih zaposlenih vezan za neadekvatna znanja i veštine za: obavljanje poslova u okviru radnog mesta; dugo vreme potrebno za uvođenje u posao; nespremnost za timski rad; nedostatak poslovnih i preduzetničkih veština i znanja; nedostatak veština komunikacije i rešavanja problema; neusklađenost teorijskih i praktičnih znanja i veština; nepoznavanje novih tehnologija; nepoznavanje sistema kvaliteta, itd. (Mašić, 2010; Apenko, 2014; Drucker, 2005; Hendry \& Pettigrew, 1992).

To zahteva promene u budućoj potražnji kadrova i zapošljavanju visoko obučenih radnika, koji će se dodatnim obuka- ma i sticanjem potrebnih kompetencija i veština osposobiti za nove tehnologije i nova radna mesta, kao i promene u visokom strukovnom obrazovanju u saglasnosti sa potrebama tekstilne industrije. Od posebnog značaja su mesto i uloga menadžmenta preduzeća tekstilne industrije u uspotavljanju veza i razvoju saradnje sa visokim tekstilnim školama strukovnih studija radi njihovog oblikovanja prema meri i potrebama tekstilne industrije, koristeći pozitivna iskustva visokoškolskih ustanova u zemljama EU. Takođe, od značaja je i razvoj partnerstva sa međunarodnim institucijama/organizacijama i njihov doprinos obuci kadrova tekstilne industrije Srbije.

\section{SPROVEDENA ISTRAŽIVANJA}

U našem istraživanju mogući uzroci problema identifikovani su u tri pravca (Poznanović, 2014):

I Mesto i uloga preduzeća tekstilne industrije, pre svega menadžmenta preduzeća, u izboru, regrutovanju i razvoju kompetentnih kadrova prema aktuelnim i budućim potrebama preduzeća. Mogući uzroci problema su:

1. nekompetentan menadžment preduzeća:

- nedovoljno edukovan/obučen menadžment;

- regrutovanje nekompetentnih kadrova od strane menadžmenta: nedostatak adekvatnih kadrova, pogrešan izbor kadrova;

- nesprovođenje, od strane menadžmenta, obuke zaposlenih/sprovođenje nedovoljne/neadekvatne obuke zaposlenih: neprepoznavanje potreba za obukom zaposlenih, izbor neadekvatnog programa obuke, izbor nekompetentnih trenera, pogrešan izbor radnika za obuku, neobezbeđivanje/nestvaranje uslova za obuku;

2. nekompetentni zaposleni:

- nesprovođenje obuke zaposlenih/nedovoljna/neadekvatna obuka zaposlenih;

- nedostatak spremnosti za permanentno učenje;

3. stalne promene tržišnih uslova, između ostalog i zbog bržih i sve učestalijih promena modnih trendova;

4. nedovoljna povezanost/saradnja sa visokim tekstilnim strukovnim školama u formiranju nastavnog plana i programa po meri tekstilne industrije i sprovođenju praktične nastave u pogonima preduzeća tekstilne industrije, gde bi se studenti, kao budući izvor radne snage tih preduzeća, obučavali u realnim uslovima procesa proizvodnje;

5. nedovoljna saradnja sa međunarodnim organizacijama/ institucijama u cilju obuke kadrova i prenošenja najnovijih znanja i iskustava iz oblasti tekstila i organizacije rada;

6. izostanak članstva u klasterima tekstilne industrije, koje bi, kroz različite oblike zajedničkog nastupa, popravilo poziciju tekstilne industrije na domaćem tržištu i odnos države prema njoj i olakšalo prodor na strano tržište, a time povećalo konkurentnost i uspešnost poslovanja.

II Oblikovanje visokih tekstilnih strukovnih škola za stvaranje kompetentnih kadrova prema potrebama tekstilne industrije. Mogući uzroci problema su:

1. neadekvatan nastavni plan i program: neusklađenost sa potrebama tekstilne industrije, nefleksibilnost - nemogućnost prilagođavanja budućim potrebama tekstilne industrije;

2. nedostatak kontrole/nedovoljna kontrola kvaliteta studijskih programa; nastave i uslova rada: izostanak samovrednovanja; nedovoljne/nekorektne eksterne kontrole; 
3. neadekvatna teorijska nastava - neusklađenost sa potrebama tekstilne industrije;

4. neadekvatna/nedovoljna praktična nastava: nedovoljna/ neadekvatna opremljenost kabineta/radionica/laboratorija, nedovoljan obim praktične nastave;

5. odnos teorijska/praktična nastava, na štetu praktične nastave;

6. nedovoljna povezanost sa preduzećima tekstilne industrije u cilju približavanja i prilagođavanja studijskih programa, nastave i uslova rada potrebama tekstilne industrije;

7. neusklađenost sa bolonjskim procesom/samo formalna usklađenost, uz nepridržavanje standarda akreditacije;

8. nedovoljna saradnja sa međunarodnim organizacijama/ institucijama u cilju edukacije kadrova;

9. neprimenjivanje pozitivnih iskustava visokih škola iz obrazovnog prostora EU;
10. izostanak članstva u klasterima tekstilne industrije.

III Spremnost međunarodnih institucija/organizacija za pružanje pomoći preduzećima tekstilne industrije i visokim tesktilnim strukovnim školama u cilju produkovanja kompetentnih kadrova za potrebe tekstilne industrije. Mogući uzroci problema su:

1. nedovoljna povezanost na relaciji: međunarodne institucije/organizacije/preduzeća tekstilne industrije/visoke tekstilne strukovne škole;

2. neadekvatna pomoć: nedostatak finansijskih sredstava, izbor neadekvatnih programa obuke, izbor neadekvatnih trenera.

$\mathrm{Na}$ osnovu identifikovanih mogućih uzroka problema, postavljen je dijagram uzroci-posledica (Ishikawa dijagram, dijagram riblja kost, Slika 1).

U radu je urađena i SWOT analiza stanja tekstilne industrije

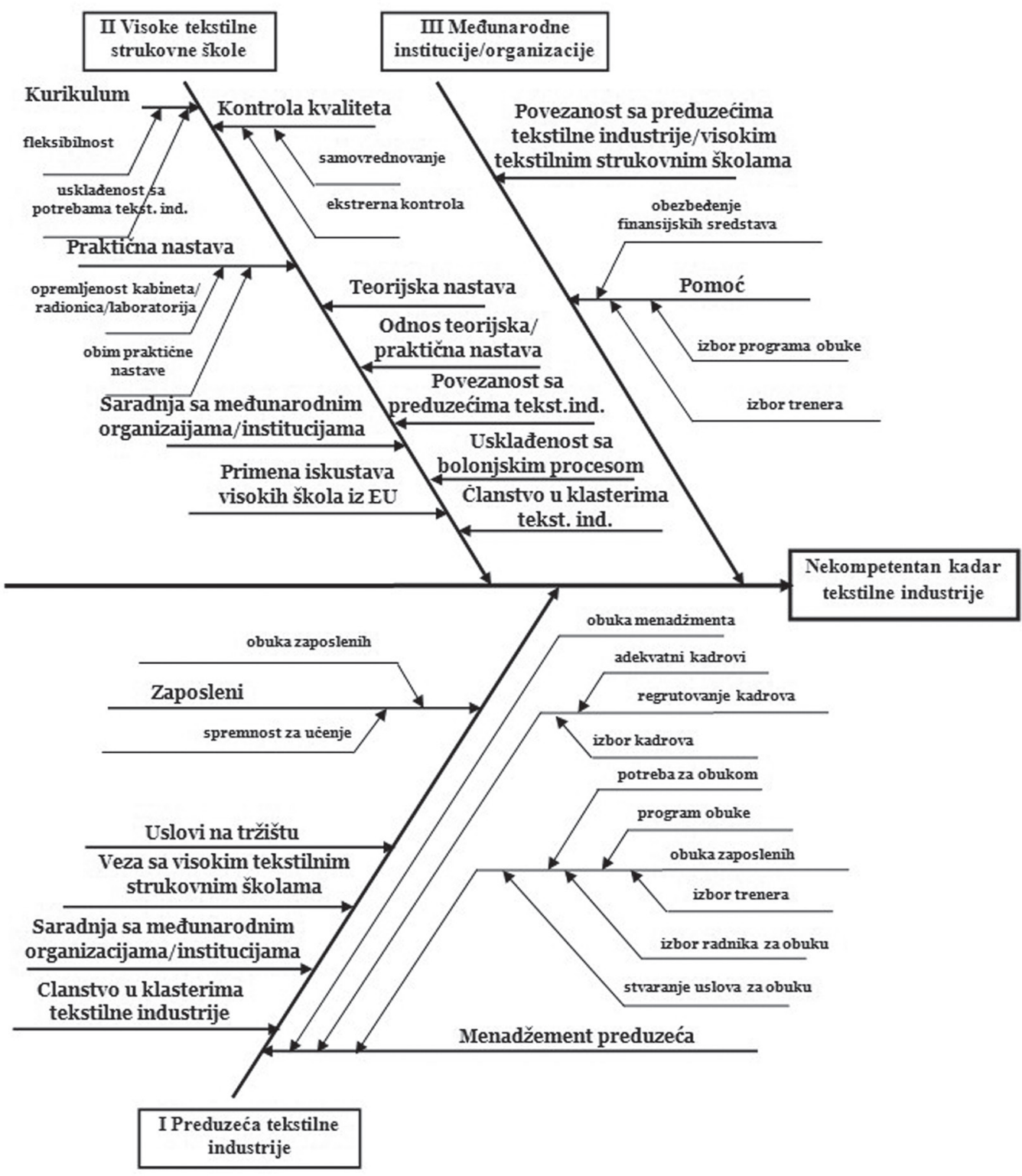

Slika 1. Dijagram uzroci-posledica (Ishikawa dijagram)

Izvor: Vulanović et al. (2003) 
Srbije. Matrica SWOT analize prikazana je u Tabeli 1.

\begin{tabular}{|c|c|c|c|}
\hline & & \multicolumn{2}{|c|}{ Tekstilna industrija Srbije } \\
\hline & & Snage (S) & Slabosti (W) \\
\hline \multirow{2}{*}{ 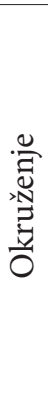 } &  & $\begin{array}{c}\text { (Suprostaviti se) } \\
- \text { nelojalna konkurencija }\end{array}$ & $\begin{array}{l}\text { (Izbeći) } \\
\text { - nedostatak obrtnih } \\
\text { sredstava } \\
\text { - nekompetentna radna } \\
\text { snaga }\end{array}$ \\
\hline &  & $\begin{array}{l}\text { (Iskoristiti) } \\
\text { - cenovna konkurentnost } \\
\text { - značajno proizvodno } \\
\text { iskustvo } \\
\text { - jeftina radna snaga } \\
\text { - blizina tržišta }\end{array}$ & $\begin{array}{c}\text { (Tražiti) } \\
\text { - dinamika tražnje na do- } \\
\text { maćem i stranom tržištu }\end{array}$ \\
\hline
\end{tabular}

Tabela 1. SWOT analiza stanja tekstilne industrije Srbije

Saradnja tekstilne industrije i visokoškolskih ustanova sa međunarodnim ogranizacijama u podizanju kompetencija zaposlenih u tekstilnoj industriji realizovana je sprovođenjem obuke od strane Organizacije za tehničku saradnju nemačke vlade (GTZ). GTZ je 2010. godine organizovao seminar „Studija vremena" prema metodologiji merenja učinka nemačkog udruženja REFA (vodeće nemačke organizacije u dizajnu radnih mesta, industrijskih organizacija i razvoju kompanija) za profesore Visoke tekstilne strukovne škole za dizajn, tehnologiju i menadžment u Beogradu i Fakulteta organizacionih nauka u Beogradu. Autori rada su, kao najuspešniji polaznici seminara, angažovani od strane GTZ i septembra 2010. godine izvršili obuku kadrova (menadžmenta prvog nivoa i neposrednih izvršilaca) osam tekstilnih preduzeća u Arilju (Miteks, Stefan, Amibo, Piroćanac, Kiko, Garman, Extera i Soda sport) (Poznanović \& Lazić, 2010), a avgusta 2011. godine jednog u Čačku (P.S. Fashion) (Lazić, 2011).

Zaposleni su obučavani u cilju ovladavanja određenim radnim tehnikama i obogaćivanja veština i sposobnosti pojedinaca, povećanja svesti o značaju optimalnog oblikovanja radnih mesta i maksimalnog povećanja efektivnosti i efikasnosti rada, sprovođenja merenja i procene učinka svakog zaposlenog radi određivanja adekvatnih nadoknada za izvršeni rad od strane menadžmenta preduzeća.

U okviru navedene obuke autori rada su sproveli i ankete menadžmenta i zaposlenih (ukupno sto ispitanika) vezane za stepen obrazovanja/kompetentnosti/veština zaposlenih, njihovo zadovoljstvo ulogom menadžmenta i njihovu spremnost za dalje usavršavanje i prilagođavanje sve bržim promenama na tržištu.

S obzirom da u Srbiji postoje samo tri visoke tekstilne strukovne škole (u Beogradu, Leskovcu i Zrenjaninu), stanje i kvalitet studijskih programa tekstilne struke, nastave i uslova rada $\mathrm{u}$ njima utvrđeni su analizom postojećih devet studijskih programa tekstilne struke, njihovih sadržaja, obima i odnosa teorijske i praktične nastave (Poznanović, 2014).

Modeli obrazovnih sistema u EU (Austrija, Nemačka, Lihtenštajn, Švajcarska; Finska, Mađarska, Holandija, Norveška, Švedska, Engleska i dr.), sa akcentom na nemački dualni model, istraživani su sa zvaničnih sajtova državnih organa/visokih strukovnih škola i iz drugih izvora (Bayerisches Staatsministerium für Unterricht und Kultus, 2014; Bayerisches Staatsministerium für Wirtschaft und Medien, CEDEFOP, 2011; Energie und Technologie, 2014; Berlin Business Location Center, 2014; British Council, 2014; Bundesministerium für Bilding und Forschung, 2013; Drimousis \& Zisimopoulos, 1988; EBC Hochschule, 2014; Federal Ministry of Labour and Social Affairs, 2014; Grollmann
\& Rauner, 2007; Kultusminister Konferenz, 2014; Maclean \& Wilson, 2009; Ministerium für Kultus, Jugend und Sport BadenWürttemberg, 2012; Pavlova, 2009; Swedish National Agency for Higher Vocational Education, 2014). Korisne informacije dobijene su i iz istraživanja vezanog za tehničko i stručno obrazovanje i obuku (TVET - Technical and Vocational Education and Training), koje je međunarodno ustavnovljeno istraživanje obrazovanja (Rauner \& Maclean, 2008).

\section{REZULTATI I DISKUSIJA}

U obe akcije obuke zaposlenih (2010. i 2011. god.) pokazana je izuzetna zainteresovanost menadžmenta svih preduzeća tekstilne industrije obuhvaćenih akcijama za edukaciju zaposlenih i unapređenje procesa proizvodnje. Obukom menadžmenta prvog nivoa za objektivno merenje udela svakog pojedinca u realizaciji proizvodnje pokazana je namera da se zaposleni motivišu za rad.

Rezultati anketa pokazali su da su od ukupnog broja anketiranih (100) samo $2 \%$ zaposlenih sa visokom (VSS) i $2 \%$ sa višom stručnom spremom (VŠS), 55\% sa srednjom stručnom spremom (SSS), dok su ostali bili nižih kvalifikacija ili bez kvalifikacija (Slika 2).

Od ukupnog broja anketiranih, samo je $28 \%$ bilo iz tekstilne struke, a ostali (72\%) su iz nekih drugih struka, obučeni za rad na svojim trenutnim radnim mestima, što je generalno odražavalo stanje u tekstilnoj industriji. Većina anketiranih (72\%) smatrala je da je svojom edukacijom dovoljno pripremljena/ kompetentna za posao koji obavlja, što je u koliziji sa odgovorom na pitanje o dodatnoj obuci: $90 \%$ ispitanika smatralo je da bi im dodatna obuka pomogla u uspešnijem obavljanju posla.

Od ukupnog broja anketiranih, 67\% zaposlenih imalo je neki vid obuke u periodu uhodavanja posla na radnom mestu - na početku rada u preduzeću. Veliki broj zaposlenih (92\%) smatrao je da je menadžment preduzeća kompetentan za posao koji obavlja, a samo $12 \%$ da menadžment preduzeća pomaže zaposlenima u napredovanju u karijeri, bez odgovora na pitanje na koji način se realizuje pomoć.

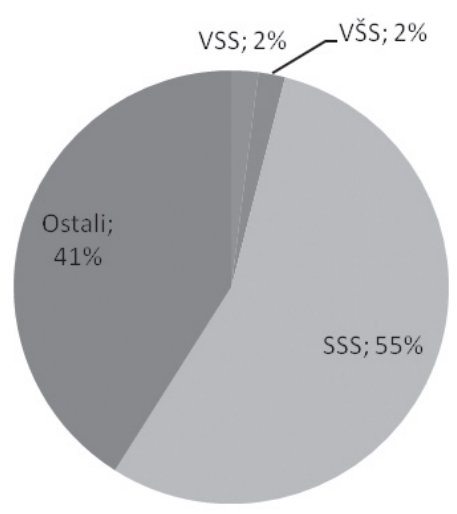

Slika 2. Kvalifikaciona struktura anketiranih zaposlenih

$\mathrm{U}$ istoj anketi postavljena su i pitanja vezana za mišljenje zaposlenih o usklađenosti nastavnog plana i programa, načina i metoda izvođenja nastave u visokoobrazovnim ustanovama sa potrebama tekstilne industrije. Predloge za unapređenje saradnje sa visokoškolskim ustanovama i promene u sistemu visokoškolskog obrazovanja imalo je samo $38 \%$ zaposlenih, a svi predlozi se mogu podvesti pod tri predloga:

1. povećanje praktične nastave u odnosu na teoretsku nastavu, 
2. izvođenje praktične nastave u pogonima tekstilne industrije i

3. promene u skladu sa praksom evropskih zemalja.

Analizom studijskih programa visokih tekstilnih strukovnih škola u Srbiji, njihovih sadržaja, obima i odnosa teorijske i praktične nastave utvrđeno je da praktična nastava (stručna praksa) u pogonima tekstilne industrije predstavlja, u proseku, oko $4 \%$ ukupne nastave koja se odvija u visokim tekstilnim strukovnim školama. Ovi podaci ukazuju na to da je pokrivenost praktične nastave obukom u pogonima tekstilne industrije daleko ispod potrebnog nivoa.

Analizom evropskog prostora obrazovnog procesa došlo se do nemačkog modela dualnog sistema stručnog obrazovanja kao najuspešnijeg i najprimenjivanijeg, koji zahteva koherentnu i sveobuhvatnu strategiju učenja tokom celog života i fleksibilnost između strukovnog, opšteg i visokog obrazovanja. U njemu su visoke strukovne škole i kompanije blisko povezane, a saradnja dopušta brz transfer svega novog u ekonomiji, tehnologiji, društvenom i naučnom razvoju u sistem obrazovanja. Takođe, obuka studenata dualnog sistema stručnog obrazovanja u pogonima ili edukacionim centrima preduzeća tekstilne industrije zauzima preko 50\% nastavnog vremena, a ista obuka se, prema potrebi, primenjuje i na već zaposlene. Osnovni princip, da svaki nivo obrazovanja mora imati mogućnost za nastavak sticanja znanja i obuke, nudi šansu dostizanja višeg nivoa obrazovanja i u strukovnom obrazovanju i kombinacijom praktičnih i teoretskih kompetencija priprema studente za učenje $\mathrm{u}$ toku celog živora i uspešnu profesionalnu karijeru.

Osnovna uloga menadžmenta preduzeća je da prepozna tekuće i buduće potrebe proizvodnog procesa i realne kapacitete raspoložive radne snage i da na osnovu toga izvrši izbor aktivnosti i osmisli plan na uspostavljanju sistema permanentne edukacije zaposlenih kao odgovor na te potrebe, da stvori sve preduslove za uspešnu realizaciju plana, da vrši monitoring procesa edukacije i procenu uspešnosti i da blagovremeno reaguje na eventualne poremećaje (promenjeni zahtevi, odstupanja od planiranih aktivnosti ili projektovanih ishoda).

\section{REZIME}

Ljudi su jedinstven, nezamenljiv resurs svakog preduzeća i predstavljaju osnovu njegovog dugoročnog uspeha i trajni izvor njegove konkurentske prednosti. Znanje, veštine, sposonosti, kreativnost zaposlenih i njihova otvorenost za permanentno obrazovanje su od izuzetne važnosti za poslovni uspeh.

$\mathrm{Na}$ osnovu sprovedenih istraživanja jasno je da je radna snaga u tekstilnoj industriji Srbije nedovoljno obučena i kompetentna za obavljanje poslova u tekstilnoj industriji, a posebno nije spremna da prati sve brže i učestalije promene na tržištu. Na nivou države neophodan je sistematski prilaz edukaciji i povećanju kompetentnosti kadrova za potrebe tekstilne industrije.

Menadžment preduzeća ima posebnu ulogu u ostvarivanju društveno odgovornog partnerstva sa visokim tekstilnim strukovnim školama, jer se kompetentna radna snaga može produkovati jedino u obrazovnom sistemu koji je prilagođen potrebama tekstilne industrije i koji je dovoljno „inteligentan” i fleksibilan da predviđa i prati buduće potrebe tekstilne industrije, imajući u vidu brze i stalne promene na tržištu i sve oštriju konkurenciju.

Visoke tekstilne strukovne škole moraju da prate potrebe tekstilne industrije za stručnim kadrom i da svoje studijske programe, način i uslove rada prilagođavaju tim potrebama, odnosno da ih oblikuju po meri tekstilne industrije. Visoke tekstilne strukovne škole, zajedno sa preduzećima tekstilne industrije, treba da, kroz saradnju sa domaćim i stranim organizacijama i institucijama iskoriste njihove resurse (finansijske, stručno-iskustvene) za povećanje kompetencija svojih studenata, budućih kadrova tekstilne industrije. To bi studentima omogućilo i sticanje novih znanja i veština, koji bi im povećali izbor i mogućnosti za zapošljavanje i dali šansu za permanentno napredovanje. Ovakva saradnja donela bi koristi i aktuelnoj radnoj snazi tekstilne industrije, jer omogućava da prate promene i idu u korak sa napretkom tehnologije i nadograđuju svoja znanja i veštine, što pozitivno utiče i na uspešnost preduzeća i njegovu konkurentnost.

Visoke tekstilne strukovne škole trebalo bi da slede pozitivna iskustva evropskog obrazovnog prostora, pre svega nemački dualni model, koji se zasniva na sprezi teorijskih znanja sa praktičnim znanjima i veštinama koje se stiču u proizvodnim pogonima tekstilne industrije ili njenim centrima za obuku, uz određenu prednost praktične nastave. To bi bila garancija da su budući kadrovi tekstilne industrije stekli potrebna znanja i ovladali veštinama koje ih čine kompetentnim za brzo i lako uključivanje u proizvodne procese i fleksibilnim za brzo prilagođavanje novim tehnologijama i brzim promenama na tržištu.

\section{LITERATURA}

Apenko, S.N. (2014). Leadership of human resources and project teams in the management of strategic changes in the organization. Strategic Management. 19(1), 28-34.

Bayerisches Staatsministerium für Wirtschaft und Medien, Energie und Technologie. (2014). Dual Vocational tranining. Retrieved 11.02.2014. from http://www.work-in-bavaria. de/en/employees/work/vocational-training/dual-vocational-training/

Berlin Business Location Center. (2014). Initial Vocational Training. Retrieved 11.02.2014. from http://www.businesslocationcenter.de/en/welcome-to-berlin/working-in-berlin/ initial-vocational-training

British Council. (2014). Education UK. Retrieved 11.02.2014. from http://www.educationuk.org/global/sub/higher-education/

Bundesministerium für Bilding und Forschung. (2013). DQR Deutscher Qualifikationsrahmen für Lebenslanges Lernen. German EQF Referencing Report. Retrieved 11.02.2014. from http://ec.europa.eu/ploteus/sites/eac-eqf/files/German_EQF_Referencing_Report.pdf

CEDEFOP. (2011). Vocational education and training at higher qualification levels. Research paper No 15. Luxembourg. Retrieved 18.01.2014. from http://www.cedefop.europa. eu/EN/Files/5515_en.pdf

Drimousis, I., \& Zisimopoulos, A. (1988). Vocational training in the textiles and clothing industries in Greese. Berlin: CEDEFOP.

Drucker, P. (2005). Upravljanje u novom društvu. Novi Sad: Adižes.

EBC Hochschule. (2014). Studium. Retrieved 11.02.2014. from http://www.ebc-hochschule.de/de/studium/bachelorstudiengaenge/fashion-luxury-retail-management.html?gclid=C jgKEAjwtZucBRD77aiiq_v4xnASJABkAg8JYEd8Qv_udeoYVjmbPeMb_PPr5zE7lT2kl6hS6PCGsfD_BwE

Federal Ministry of Labour and Social Affairs. (2014). Vocational Training in Germany. Retrieved 11.02.2014. from http:// www.make-it-in-germany.com/en/working/prospects-ingermany/vocational-training-in-germany/

Grollmann, P., \& Rauner, F. (2007). International Perspective on Teachers and Lecturers in Technical and Vocational Education. Berlin: Springer. 
Hendry, C., \& Pettigrew, H.C. (1992). Patterns of Strategic Change in the development of human resource management. British Journal of Management. 3(3), 137-156. DOI: 10.1111/j.14678551.1992.tb00041.x

Jovanović, R. (2005). Tekstilna industrija Srbije. Beograd: G17 Institut

Keane J., \& te Velde D.W. (2008). The role of textile and clothing industries in growth and development strategies. Retrieved 21.01.2014. from www.odi.org.uk/resources/docs/3361.pdf

Kultusminister Konferenz. (2014). The Education System in the Federal Republic of Germany. Retrieved 11.05.2014. from http://www.kmk.org/information-in-english/the-education-system-in-the-federal-republic-of-germany.html

Lazić, B. (2011). Izveštaj o stanju organizacije rada u „P.S. Fashion" Čačak. Beograd: DTM.

Maclean, R., \& Wilson, D. (2009). International handbook of education for the changing world of work: Bridging academic and vocational education. Dordrecht: Springer.

Mašić, B., et al. (2010). Menadžment: principi, koncepti i procesi. Beograd: Univerzitet Singidunum

Mein Bildungs Weg. (2014). Bayerisches Staatsministerium für Unterricht und Kultus. Retrieved 11.02.2014. from http:// www.mein-bildungsweg.de/uebersicht_en.php

Ministarstvo ekonomije i regionalnog razvoja Republike Srbije/ Republički zavod za razvoj. (2011). Strategija i politika razvoja industrije Republike Srbije 2011-2020.

Ministarstvo za nauku i tehnologiju Republike Srbije. (2010). Strategija naučno-tehnološkog razvoja Srbije 2010-2015.

Ministerium für Kultus, Jugend und Sport Baden-Württemberg. (2012). Vocational Schools. Retrieved 11.02.2014. from http://www.schule-bw.de/schularten/berufliche_schulen/02_12_2012_vocational_schools.pdf

Pavlova, M. (2009). Technology and vocational education for sustainable development: Empowering individuals for the future. Dordrecht: Springer.
Poznanović, S. (2014). Doktorska disertacija: Doprinos menadžmenta preduzeća razvoju društveno odgovornog partnerstva i oblikovanju visokih strukovnih škola prema potrebama tekstilne industrije. Brčko: Internacionalni univerzitet Brčko distrikt $\mathrm{BiH}$, Fakultet za menadžment

Poznanović, S., \& Lazić, B. (2010). Izveštaj o sprovedenoj edukaciji zaposlenih u osam preduzeća tekstilne industrije u Arilju. Beograd: DTM.

Poznanović, S., \& Muratović, Š. (2014). Significance of company management in the development of textile industry staff. U: 4rd International Conference "Economics and Management - Based on New Technologies", EmoNT 2014. 12-12. Jun 2014. Str. 289-296. Vrnjačka Banja: TCIP Publisher Ltd.

Rauner, F., \& Maclean, R. (2008). Handbook of technical and vocational education and training research. New York: Springer.

Službeni glasnik RS. (2007). Strategija razvoja stručnog obrazovanja u Republici Srbiji. Službeni glasnik RS br. 1.

Stamenković, S., et al. (2010). Postkrizni model ekonomskog rasta i razvoja Srbije: 2011-2020. Beograd: USAID, SEGA projekat.

Swedish National Agency for Higher Vocational Education. (2014). Higher Vocational Education. Retrieved 11.02.2014. from http://studyinsweden.se/study-information/highervocational-education/

UNEP. (1994). The Textile Industry and the Environment. Retrieved 22.01.2014. from http://www.faculty.ait.ac.th/visu/Data/Publications/Chapters\%20\&\%20books/The\%20Textile\%20Industry\%20and\%20the\%20environment.pdf

Vulanović, V., et al. (2003). Metode i tehnike unapređenja procesa rada: statističke, inženjerske, menadžerske. Novi Sad: Fakultet tehničkih nauka. 